\title{
Food Supply and Urban Gardening in the Time of Covid-19
}

\author{
Silvana NICOLA ${ }^{1 *}$, Antonio FERRANTE ${ }^{2}$, Giacomo COCETTA ${ }^{2}$, Roberta BULGARI ${ }^{2}$, Carlo NICOLETTO ${ }^{3}$, \\ Paolo SAMBO ${ }^{3}$, Andrea ERTANI ${ }^{1}$ \\ ${ }^{1}$ University of Turin, Department of Agricultural, Forest and Food Sciences, DISAFA, Via Leonardo da \\ Vinci, 44 - Largo Paolo Braccini, 2 - 10095 Grugliasco (TO), Italy \\ ${ }^{2}$ University of Milan, Department of Agricultural and Environmental Sciences - Production, Landscape, \\ Agroenergy, DiSAA, Via Celoria, 2 - 20133 Milano (MI), Italy \\ ${ }^{3}$ University of Padua, Department of Agronomy, Food, Natural resources, Animals and Environment, \\ DAFNAE, Agripolis - Viale dell'Università, 16 - Legnaro (Padova), Italy \\ *corresponding author: silvana.nicola@unito.it
}

BulletinUASVM Horticulture 77(2) / 2020

Print ISSN 1843-5254, Electronic ISSN 1843-5394

DOI:10.15835/buasvmcn-hort: 2020.0051

\begin{abstract}
The pandemic caused by Covid-19 has highlighted the vulnerability of the agrifood system. The urgent need to supply fresh food has arisen everywhere. Lockdown slowed down the fresh vegetables supply in the long distance distribution chains. In addition, the total confinement occurred in many countries left the people not only distressed, but also in the need to divert daily spare time to a new home gardening vitalization. During the pandemic, sales in local and street markets declined dramatically, while most purchases became concentrated in supermarkets. This fact has increased the risk of crowdedness and thus contamination or regulated entrances in the supermarkets, or left communities in small towns with limited access to food supply due to the lack of big grocery stores. Gardening can increase opportunities for local and fresh food availability. Scaling-up local food production becomes important to increase resilience of communities. The pandemic may represent an important opportunity to enhance a new era of gardening with modern technology along with traditional systems.
\end{abstract}

Keywords: home food production, lockdown, pandemic, urban horticulture

\section{Introduction}

The pandemic caused by Covid-19 has highlighted in the advanced countries the vulnerability of the agrifood system, interconnected with the worldwide supply chain and the local demand for pickers in the field and capillary delivery to the consumers. In less developed countries, the lockdown and transport restrictions disrupted the links between rural and urban areas, threatening the cities' food security (Wetaya, 2020). The urgent need to supply fresh food, especially fresh products, $m$ to households has arisen everywhere. In addition, the total confinement occurred in many countries left the people not only distressed, but also in the need to divert daily spare time to a new home gardening vitalization, considering this activity as a 'productive gardening', as opposed to getting bored or feeling unproductive (Montefrio, 2020) and to reduce stress and anxiety. Indeed, the natural growth rhythms of plants help to reduce the stresses (Panten and Ruhnke, 2006). Considering that food access may become an issue due to the continuation of the pandemic or future crises in urban areas of many countries (Hanna, 2020), the present work aimed to analyse the increase of urban gardening in the communities as 
a reaction to the confinement due to Covid-19 and the prospects for an enduring resilience related to this new situation.

\section{Materials and methods}

The present communication is a literature review in the websites related to cities and communities reactions to the Covid-19 pandemic, covering various cCountries and social contexts characterized by a different food security situation. Several keywords, including urban horticulture, resilience, fresh vegetables, Covid-19 and pandemic, were used. Subsequently, the information was compared and evaluated individually using a critical approach that allowed the information to be integrated. Scientific literature review has been considered for analysis of therapeutic horticulture and system resilience. Where available, data on sales and consumption of horticultural products have been included.

\section{Results and discussions}

In Italy, during the peak of the pandemic, as indicated by Italian Institute of Services for the Agricultural and Food Market (ISMEA, 2020), sales in local and street markets declined dramatically, while some $50 \%$ of purchases became concentrated in big grocery stores and supermarkets. This fact has increased the risk of crowdedness and thus contamination or regulated entrances in the supermarkets, or left communities in small town with limited access to food supply due to the lack of big grocery stores. At the same time, there has been an increase in home delivery through on-line purchases $(+160 \%)$ limited only by the lack of supply (ISMEA, 2020). In addition, delays and inadequacy of the big retailers were registered, causing stoppage of the systems. Fresh vegetables need well organised distribution chains for reaching in short period the final markets, without compromising their quality and nutrition value. Frozen vegetable sales increased by $25 \%$ during the peak of the lockdown and continued to stay higher than the year before $(+14.6 \%)$ after the lockdown (FreshPlaza, 2020). The closure during the lockdown of the all Horeca sector was accompanied by a $6 \%$ increase of home food consumption (ISMEA, 2020).
In the USA, the disruption of the meat supply chain caused spikes in prices and limit in items consumers could buy (Forbes, 2020a). Big retailers such as Alberston reached out indoor farming companies to increase their offer of indoor-grown produce from the vicinity (Forbes, 2020b). Several indoor farming startups raised millions of dollars and boosted the production to supply more produce to relieve store shortages (Forbes, 2020b).

In Canada, in the State of Ontario and in the city of Toronto, new community and allotment gardens were opened to make fresh food available to people who live in apartments or condominiums and who lack the resources to buy fresh fruits and vegetables (Stahlbrand and Roberts, 2020). In addition, individuals and markets have set up online ordering from local farmers with drop-off sites across the city. The pandemic has created an urgency in the community to appeal to advance a progressive agenda for economic recovery after the pandemic. Non-profit and for-profit food organizations are driving this appeal, promoting green infrastructures and offering free course on farming green roofs. Initiatives are developing, such as food projects that include greenhouses for long-term care homes, wildlife buffer zones in the city, street vending, gardens in the schools.

In Canada, in the city of Montreal, Lufa Farms opened in August 2020 its fourth rooftop greenhouse of 15 ha, the largest in the world, where vegetables such as tomato, eggplants, lettuce and other produce are grown. Due to the Covid-19 pandemic, Lufa Farms doubled its demand since March 2020 to fulfil the requests for local and fresh products. The company has 500 employees, but 200 were hired during Covid- 19 to increase vegetable production, tripling its home delivery capacity.

In the Philippines, there has been a proliferation of home gardens during the pandemic, making some observers believe that this trend could continue after the pandemic and enhance food security to the community (Montefrio, 2020). Montefrio (2020) did a Google trend analisys and found that the Philippines ranked among the top ten geographic locations where the term 'gardening' was most popularly searched from February to May 2020. Although the country has a long history of gardening, since the XVI century onward, ranging from kitchen gardens to 
ornamental gardens, from home to community gardening initiatives, the Covid-19 seems to have led to a great expansion of the activity. During the lockdown, especially the impoverished population faced food insecurity, due to income disruptions, prompting the demand for food aid from the government. In turns, government agencies and non-government organizations distributed seeds to encourage home gardening, contributing to the relief of the population (Cabico, 2020; Montefrio, 2020). Many home gardeners who did not have backyard space shifted to soilless culture by using all sort of containers available at home (plastic bottles, cookie boxes, cans, etc.), leading to the 'Container Gardening'. Information and instructive material was spread in the social media by organizations and volunteers (e.g. Urban Vegetable Gardening of the Philippines, Facebook, https://www.facebook.com/urbangardeningph/).

Urban garden have been also set up in Manila to feed herbivore or plant-eating animals in the Manila Zoo during the Covid-19 pandemic to overcome the feed uncertain times (Cayabyab, 2020).

In the UK, gardening businesses have been booming during the past months. Britain's Royal Horticultural Society has seen a five-fold rise in queries for gardening advice on its website during the lockdown (Good News Network, 2020). Even sales of houseplants increased, most probably to overcome the confined days of the lockdown. The need for ornamentals and flowers did not probably decrease, but the availability on the market was almost zero. In April, sales at Royal Flora Holland dropped on average $50 \%$ each week from the previous year (Craig, 2020). This meant many growers were throwing away up to $80 \%$ of their production, given the high perishability of flowers.

In Uganda, the food security has been threatening greatly in cities during the lockdown due to the transport restrictions that disrupted the logistics of the food between rural and urban areas (Wetaya, 2020). The reaction of the government was the distribution of food to the citizens, especially in Kampala, Uganda Capital, but this was far from sufficient. The urban and peri-urban agricultural sector however has been a safeguard of the food supply chain for the city. It is estimated that during the lockdown, more than $65 \%$ of the vegetable supplies of Kampala have been provided by the sector. This strategy occurred in other cities in the East African region, alleviating the lack of fresh food in particular because the Covid-19 lockdown. In Kampala, vertical farming in small spaces is thought at the local Mushana Agribusiness School, and urban farming skills are obtained by several youth groups. Wetaya (2020) reports that urban and peri-urban agriculture, including vertical gardens and hydroponics, gave benefit to several cities in Africa, such as Nairobi (Kenya), supplying about 30\% households, and Dar es Salaam (Tanzania), where urban agriculture comprises about $60 \%$ of the informal economic sector.

\section{Perspectives and conclusions}

This review shows that through an integrated study of different aspects, it is possible to demonstrate the true value of home gardens and the extent of their potential contribution in the event of a pandemic. Indeed, the prime objective of urban gardens often differs from one of the food production with this being the means by which other outputs are achieved for the body, the mind and the mood, able to provide cognitive functioning, emotional well-being, physical, social and creative advantages. The relief provided during confinement by gardening may have contributed in giving a sense of reality, making feeling of doing meaningful activities, helping in reducing stress and anxiety. Many of the positive aspects of the therapeutic horticulture can be used and exploited to overcome the odds of the pandemic; at the same time, home food production and gardening can increase opportunities for scattered, local and fresh food availability in a beautiful self-made landscape, helping the resilience of the system and increasing at the same time the local food security.

The Covid-19 pandemic has highlighted barriers accessing community gardens, revealing the urgent needs for more localized growing plots, either in the own backyard or on the own balcony. Scaling-up local food production becomes important to increase resilience of communities. The increased spare time of many individuals due to the closure of the workplaces might become an opportunity to be engaged in home gardening for food production. The foreseen reduction of labour working hours planned by several States to reduce the impact of the economic crisis might drive positive benefits from increased gardening. 
The closure of the schools certainly caused and will cause some educational gap in an entire generation if the pandemic will last. There is a need to assist the kids and teenagers in their path to understand the beauty of the outdoor and of gardening, with positive implications also on their food education. There should be a great opportunity to have a garden for every school, ideally with a greenhouse, so fresh food can be grown year round and daily entraitenement can occur, freeing parents' custody.

The pandemic might have been the boost for a boom of the AgTech companies and may represent a starting point to enhance an era of home food production and gardening with modern technology along with traditional growing systems. Future research might be addressed In light of these considerations, further research will be essential to study innovative solutions to meet the needs of the users of urban gardens, in term of technical solutions and svegetable species of plants to be grown. Ranging from microgreens to small vegetables, from herbs to roses, from climbing fruits, such as squashes and watermelon, to tomato, from allium bulbs to flower bulbs, from soft fruits to citrus plants, growing systems can include pots, trays, garden boxes, up to green walls, either edible or for landscaping. Ultimately, transforming a full green lawn into small plots for flowers and food fresh production can give a new wave to urban horticulture. The contribution that community and allotment gardens can make to social wellbeing within cities justifies a call for further recognition of these spaces in urban planning policy. For these reasons, it would be desirable that the different states make different strategies for their enhancement at the regulatory level.

\section{References}

1. Cabico GK(2020).Community gardens can help feed people post-pandemic. https://www.philstar.com/business/ agriculture/2020/05/08/2012553/community-gardenscan-help-feed-people-post-pandemic. Accessed 15.09.20.

2. Cayabyab MJ (2020). Manila Zoo Sets Up Urban Garden To Feed Animals During COVID-19 Pandemic. https://www. onenews.ph/manila-zoo-sets-up-urban-garden-to-feedanimals-during-covid-19-pandemic. Accessed 15.09.20.

3. Craig V (2020). COVID-19 wilts global flower trade, even as spring weather blossoms. https://www.marketplace. org/2020/04/29/covid-19-flower-industry-springtime/. Accessed 28.08.20.

4. Forbes (2020a). https://www.forbes.com/sites/ andriacheng/2020/05/05/with-crimped-animal-meatsupply-coronavirus-may-open-big-consumer-appetitefor-plant-based-meat-from-beyond-meat-impossiblefoods/\#454231312920. Accessed 28.08.20.

5. Forbes (2020b). https://www.forbes.com/sites/ andriacheng/2020/08/13/coronavirus-may-lead-tomore-indoor-grown-produce-coming-to-your-localsupermarkets/\#f1d845126335. . Accessed 28.08.20.

6. FreshPlaza (2020). https://www.freshplaza.it/article/ 9238776/surgelati-la-crescita-va-oltre-l-effetto-coronavirus/. Accessed 28.08.20.

7. GoodNewsNetwork (2020). Gardening is Booming During This Pandemic - and You Can Still Start Planting in July. https://www.goodnewsnetwork.org/gardening-isbooming-during-this-pandemic/. Accessed 28.08.20.

8. Hanna K (2020). Crisis Gardening: Addressing Barriers to Home Gardening during the COVID-19 Pandemic. https:// www.sustain.org.au/wp-content/uploads/2020/06/ Crisis-Gardening-Addressing-Barriers-to-HomeGardening-during-the-COVID-19-Pandemic.-.pdf. Accessed 02.09.20.

9. ISMEA (2020). www.ismea.it. Accessed 28.08.20.

10. Montefrio MJ (2020). Interrogating the "productive" home gardener in a time of pandemic lockdown in the Philippines. Food and Foodways, 28(3): 216-225.

11. Panten H, Ruhnke P (2006). Flowers and Plants - more than just beautiful... AIPH, International Association of Horticultural Producers. http://aiph.org/wp-content/ uploads/2015/04/7_AIPH-Brochure-more-than-justbeautiful.pdf. Accessed 02.09.20.

12. Stahlbrand L, Roberts W (2020). Local food system responses to COVID-19: Toronto and its city region. Ruaf, May 12. https://ruaf.org/news/local-food-systemresponses-to-covid-19-toronto-and-its-city-region/. Accessed 02.09.20.

13. Wetaya R (2020). Urban agriculture thriving in East Africa during Covid-19. Cornell AllianceForScience, August 3. https://allianceforscience.cornell.edu/blog/2020/08/ urban-agriculture-thriving-in-east-africa-duringcovid-19/. Accessed 28.08.20. 